Forthcoming in Religious Studies. Please cite published version.

\title{
The Copernican Principle, Intelligent Extraterrestrials, and Arguments from Evil
}

\begin{abstract}
The physicist Richard Gott defends the Copernican principle, which claims that when we have no information about our position along a given dimension among a group of observers, we should consider ourselves to be randomly located among those observers in respect to that dimension. First, I apply Copernican reasoning to the distribution of evil in the universe. I then contend that evidence for intelligent extraterrestrial life strengthens four important versions of the argument from evil. I remain neutral regarding whether this result is a reductio of these arguments from evil or the statement of a genuine evidential relationship.
\end{abstract}

Keywords: Copernican principle; problem of evil; extraterrestrial life; Richard Gott 


\section{The Copernican Principle, Intelligent Extraterrestrials, and Arguments from Evil}

The physicist Richard Gott defends the Copernican principle, which claims that when we have no information about our position along a given dimension among a group of observers, we should consider ourselves to be randomly located among those observers in respect to that dimension (Gott (1993); (1994); (1996); (2001)). In this paper, I contend that the Copernican principle has implications for the likely distribution of evil in the universe. As a result, there is an important class of versions of the argument from evil - asymmetrical arguments from evil - that, if cogent, are strengthened by evidence for the existence of abundant intelligent extraterrestrial life. I remain neutral regarding whether this result is a reductio of these versions of the argument from evil or the statement of a genuine evidential relationship.

\section{The Copernican principle and the worst evils in the universe}

Gott's use of the Copernican principle can be illustrated by his primary application of it: the longevity of the human species. If the apocalypse happens tomorrow, we are in an unlikely location in time: at the very end of the human race. If humans survive trillions of years and colonize the galaxy, then we are also in an unlikely location in time and space: earthbound at the very dawn of humanity. Consequently, we shouldn't put much credence in the idea that we are in either one of these scenarios. Gott observes that the Copernican principle implies that our probability that we are currently in the middle $50 \%$ of the lifespan of humanity should be .5 , the middle 95\%, .95 and so on. ${ }^{1}$ He assumes modern humans came into existence 200,000 years ago. If 200,000 years is at the upper end of the middle $95 \%$ of human history, we have 5,100 years

remaining. If it is at the lower end, we have 7.8 million years remaining. He concludes there is a 
$95 \%$ chance we will last at least 5,100 more years but not longer than 7.8 million more years. ${ }^{2}$

Gott has also applied Copernican reasoning to non-temporal dimensions. For example, he argues there is a $95 \%$ chance that you will test in the middle $95 \%$ of the population on a test for a newly discovered enzyme (Gott (1996), 148), and a 95\% chance that you were born in a country with a population greater than 5.8 million (Gott (2001), 212).

I will apply the Copernican principle to two non-temporal dimensions: height and value. First, suppose we were members of a small tribe not in communication with other peoples on the planet. If we believed we were alone on the planet, we would think that our tribe had the tallest person on the planet. We subsequently learn there are many other tribes on the planet. We should then infer that our tallest member is very likely not the tallest on the planet.

Second, suppose we discover that noetism (van Inwagen (1996), 168) is true: there are many intelligent extraterrestrials. ${ }^{3}$ We should then think it very likely that there are intelligent extraterrestrials whose most unfortunate members experience more evil ${ }^{4}$ than the most unfortunate humans, whose most fortunate members experience more good than the most fortunate humans, and whose worst calamities are worse than the worst human calamities.

We can use Copernican reasoning to make specific calculations of the probabilities of certain kinds of outcomes. Gott's reasoning as outlined above is equivalent to Bayesian inference using a prior due to Harold Jeffreys (Gott (1994); Monton \& Kierland (2006)). The Jeffreys prior states that when we have no other information, the probability that the positive maximum value along a dimension is a given number is proportional to the inverse of that number (Jeffreys (1939)). Suppose I receive a score on a test for the newly discovered enzyme, but have no idea what the range is. The Jeffreys prior states that my probability that the maximum score on the test is 5 should be proportional to $1 / 5$; that it is $10,1 / 10$, etc. When I learn that my score is, say, 4.6 , I 
revise my probabilities by assigning 0 to the claims that the maximum score is below 4.6 , normalizing, and updating by Bayes's rule.

Here's how this works in the case of evil. Suppose noetism is true and the local maximum of evil on Earth is 10 standard badness units (SBUs). Where $E_{\mathrm{x}}=$ the claim that the maximum evil in the universe is $\mathrm{x}$ SBUs, the Jeffreys prior tells us that $\mathrm{P}\left(\mathrm{E}_{\mathrm{x}}\right) \propto \frac{1}{x}$. We will conditionalize on $\mathrm{O}_{10}$, the claim that the maximum evil observed is 10 SBUs. By Bayes's Theorem, where $\mathrm{P}^{*}$ represents our new probability function, $\mathrm{P} *\left(\mathrm{E}_{\mathrm{x}}\right)=\mathrm{P}\left(\mathrm{E}_{\mathrm{x}} \mid \mathrm{O}_{10}\right)=\left(\mathrm{P}\left(\mathrm{O}_{10} \mid \mathrm{E}_{\mathrm{x}}\right) \times \mathrm{P}\left(\mathrm{E}_{\mathrm{x}}\right)\right) / \mathrm{P}\left(\mathrm{O}_{10}\right)$. By the Jeffreys prior, $\mathrm{P}\left(\mathrm{E}_{\mathrm{x}}\right) \propto \frac{1}{x} . \mathrm{P}\left(\mathrm{O}_{10} \mid \mathrm{E}_{\mathrm{x}}\right)$ will be 0 if $\mathrm{x}<10$; otherwise $\propto \frac{1}{x}$ (again because of the Jeffreys prior $)$. It follows that $\mathrm{P}\left(\mathrm{E}_{\mathrm{x}} \mid \mathrm{O}_{10}\right) \propto \frac{1}{x^{2}}$ in all cases where $\mathrm{x} \geq 10$. To normalize, we consider what we know for certain: that the maximum evil in the universe is at least 10 SBUs: $\mathrm{L}_{10} . \mathrm{P} *\left(\mathrm{~L}_{10}\right) \propto \int_{10}^{\infty} \frac{1}{x^{2}} d x=\frac{1}{10}$. Since we know $\mathrm{P} *\left(\mathrm{~L}_{10}\right)=1$, the normalization factor is 10 . Finally, we are ready to calculate that $\mathrm{P}^{*}\left(\mathrm{~L}_{\mathrm{x}}\right)=10 \int_{x}^{\infty} \frac{1}{x^{2}} d x=\frac{10}{x}$ for all $\mathrm{x} \geq 10$ (Monton \& Kierland (2006), 22-23). 


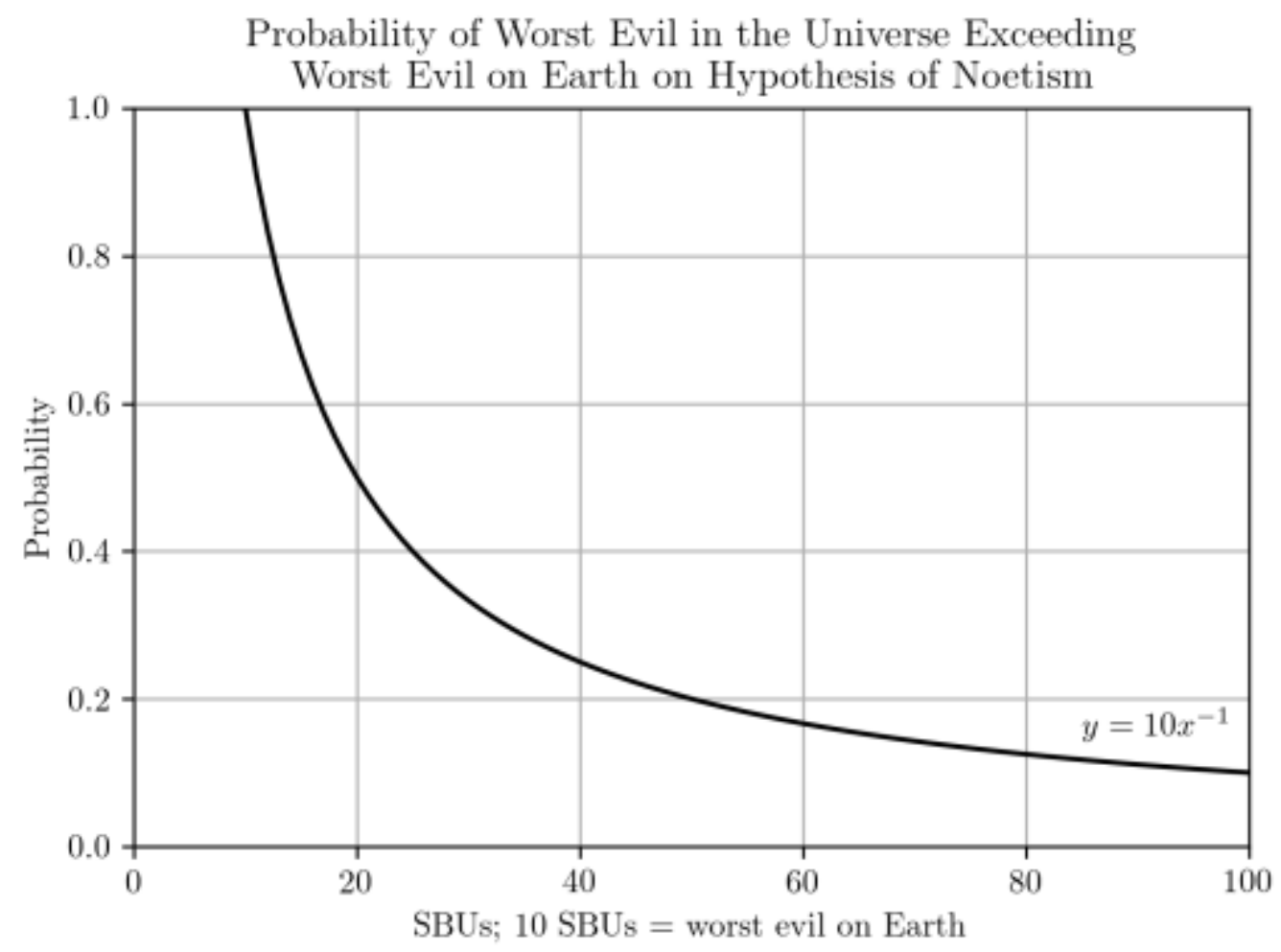

Figure 1

This is a sobering result. Take whatever you consider to be the worst evil in human history. There is an $80 \%$ chance that something at least one quarter again as bad has happened somewhere else in the universe, and a 50\% chance that something at least twice as bad has happened. Even if we stick to Gott's favoured threshold of $95 \%$, we should be very confident that the worst evil in the universe is at least 10.52 SBUs. Considering how awful the worst evils in human history have been, a $5.2 \%$ increase is significant.

Now there are cases where it seems absurd to use the Jeffreys prior. The tallest human ever recorded was 8 feet, 11 inches tall. Using the Jeffreys prior, we can calculate that there is a $1 \%$ chance that the tallest intelligent extraterrestrial is more than 890 feet tall. This does not seem plausible. What has gone wrong? The only situations in which we should exclusively use the Jeffreys prior are ones in which we have no information whatsoever. We know that to support terrestrial life, a planet requires gravity sufficiently strong to retain an atmosphere, and 
gravity sufficient to retain an atmosphere limits the height a creature can attain before it collapses under its own weight. When we have information about the question at hand, we do not adopt a pure Jeffreys prior, but rather employ a 'Gott-like shift', moving our probabilities towards the unrestricted Jeffreys prior while retaining the information we have (Monton \& Kierland (2006), 31-34). This is why we do not infer that there is a $1 \%$ chance that there are intelligent extraterrestrials at least 890 feet tall, yet still think there are very likely intelligent extraterrestrials taller than us.

We have some information about evil on other inhabited planets, but not enough to prevent the use of Copernican reasoning. There is a limit to how debilitating pain can be in creatures that survive long enough to reproduce. Moreover, if things were too bleak on a given planet, intelligent extraterrestrials would be less likely to have evolved in the first place. However, these factors tending to limit the evil on other planets may be balanced out by the fact that we know that we have, so far, survived. There is no such anthropic constraint for other intelligent beings, some of whom may have been wiped out by a calamity greater than any we have faced. Furthermore, just because a species evolved in survivable circumstances does not mean its current circumstances are benign.

Another potential source of information about value on other planets is our knowledge of human population size. According to Copernican reasoning, it is very likely that a randomly selected human will have been born in a country with a population greater than the typical country, because larger groups of humans contain many more humans collectively than smaller groups of humans, and we are to consider ourselves randomly selected humans (Gott (2001); Simpson (2016)). (Of course, different distributions of population are possible - for example, there could be one large country and very many small countries - but most distributions are ones 
in which the majority of individuals live in the most populous countries.) For the same reason, so long as there are intelligent extraterrestrials, we should expect that our planet has a higher total population of intelligent beings than the typical planet with intelligent extraterrestrials (Simpson (2016)). This allows us to make certain inferences about goods and evils that have a relationship with population size. For example, we are likely to face worse environmental challenges, make scientific discoveries and achievements of creative genius at a greater rate, have better medicine and food supplies, and have more wars than a typical intelligent species. A full analysis of the implication of a greater-than-typical population is complex and lies outside of the scope of this article. However, even if a greater-than-typical population likely leads to greater-than-typical evils, the same reasoning that leads us to conclude that the Earth likely has a higher population than a typical planet inhabited by intelligent beings will lead us to conclude that there are likely planets with even higher populations, which - on the very hypothesis being assumed - would likely lead to greater evils than we have witnessed on Earth. ${ }^{5}$ I conclude that, on the assumption of noetism, there is a strong Gott-like shift towards thinking it very likely that there are evils in the universe significantly worse than the worst evils on Earth, as well as goods significantly better than the best goods on Earth.

\section{Asymmetrical arguments from evil}

I have contended that if noetism is true and the Copernican principle is true, we should broaden the range of value of good and evil we take to be instantiated in the universe symmetrically: we should think there are likely worse evils than the worst evils on Earth (see

figure 1), but we should also think there are likely better goods than the best goods on Earth. In this section, I argue that this symmetrical broadening of the range of good and evil strengthens 
four arguments from evil prominent in the literature, if these arguments are cogent in the first place. Because according to these arguments, our symmetrical broadening of the range of good and evil favours the atheist over the theist, I will call these arguments asymmetrical.

In the final section, I consider the possibility that it is absurd for arguments from evil to be asymmetrical. If it is indeed absurd, then the current section constitutes a reductio of these four arguments from evil. If it is not absurd, then this section argues that in the next several decades, as we gather evidence about the frequency of atmospheric biomarkers on habitable exoplanets (NASA (2014); NASA (2015)), we will get empirical evidence that is relevant to the question of whether God exists, to the degree that these arguments from evil are plausible. Either way, the result is significant.

The four arguments from evil with which I am here concerned are each founded upon two propositions. The first proposition states a necessary condition on worlds created by a perfect God. It is either necessarily true or necessarily false, but our subjective credence in it might take intermediate values between 0 and 1, just as we might be highly confident of, but not certain of, Goldbach's Conjecture. The second proposition is the empirical claim that the actual world does not meet this condition. The arguments from evil with which I am concerned contend that we should increase our credence in at least one of these propositions, and as a result, reduce our credence in the claim that a perfect God exists.

Any argument from evil whose condition on divine world creation invokes only properties of the aggregate value of the universe - say, that it exceeds a certain threshold (Plantinga (1977), 63; see Monton (2010), 115-117) - will be symmetrical. Aggregate value is calculated by adding together all the positive value in the universe and subtracting all the negative value. Let's suppose that I think that God would only create universes with an aggregate 
value of at least 10 SGUs (Standard Goodness Units). I argue that Earth has an aggregate value of only 5 SGUs, and thus that God does not exist. If I then receive evidence for noetism, I will symmetrically broaden my opinion about the range of value in the universe. My argument for atheism will be unaffected because this symmetrical broadening does not affect my assessment of the universe's aggregate value. For every additional evil I infer is likely, there is likely a comparable good. ${ }^{6}$

However, we usually consider more than aggregate value when evaluating the moral qualities of an action because we do not generally think you can simply offset the performance or permission of evil actions by the performance or permission of good actions (Chisholm (1990), 57). For this reason, I focus my attention on four conditions on divine world creation that appeal to something more than aggregate value. I will argue that these conditions can be used to generate arguments from evil that according to Copernican reasoning are strengthened by evidence for noetism. ${ }^{7}$

No gratuitous evil condition: a world created by a perfect God would not contain evil the permission of which is not necessary for a greater good or the prevention of a worse evil (Rowe (1979); for critique, see, e.g., Hasker (1992); Zagzebski (1996); Trakakis (2008); and the authors defending the remaining three conditions).

Weak patient-centred condition: a perfect God would ensure that every individual lives a life worth living (Draper (2004); Marilyn McCord Adams (1999); Swinburne (1998); Tracy (1992), 310; see Kraay (2013), 238-239; for critique, see, e.g., Cohen (2013), 82). 
Strong patient-centred condition: a perfect God would ensure that every evil suffered by an individual is part of the best available means for the overall improvement of her life (Stump (1985), 411; (2010), 456; for critique, see, e.g., Hasker (1992); Tracy (1992)).

Threshold condition: worlds created by a perfect God do not contain evils so horrific no reason could justify their permission (Dostoevsky (1990); Cohen (2013); Rowe (1996), 270).

Each of these four conditions can be used to fund an argument from evil using subjective probabilities. I will illustrate with the threshold condition. Let $\mathrm{V}_{\mathrm{T}}$ be the proposition that the threshold condition is violated, i.e. that there is evil so horrific no reason could justify its permission, and let $\mathrm{G}$ be the proposition that a perfect God exists. Prior to hearing the argument from evil based on the threshold condition, an agent's creedal state $\mathrm{P}$ is:

$$
\begin{aligned}
& P\left(G \mid V_{T}\right)=s \\
& P\left(G \mid \sim V_{T}\right)=r \\
& P\left(V_{T}\right)=q \\
& P(G)=q \times s+(1-q) \times r \quad \text { (by the Theorem of Total Probability) }
\end{aligned}
$$

If the agent is certain of the threshold condition, $P\left(G \mid V_{T}\right)=0$; otherwise, $P\left(G \mid V_{T}\right)$ may take a positive value. The argument from evil seeks to reduce the agent's credence in $\mathrm{G}$ by convincing them to lower $\mathrm{P}\left(\mathrm{G} \mid \mathrm{V}_{\mathrm{T}}\right)$, raise $\mathrm{P}\left(\mathrm{V}_{\mathrm{T}}\right)$, or both. ${ }^{8}$ If the agent updates to a new credal state $\mathrm{P}^{\prime}$ such that:

$$
\begin{aligned}
& \mathrm{P}^{\prime}\left(\mathrm{G} \mid \mathrm{V}_{\mathrm{T}}\right)=\mathrm{s}^{\prime} \quad \text { (if the argument is cogent, } \mathrm{s}^{\prime}<\mathrm{r} \text { ) } \\
& \mathrm{P}^{\prime}\left(\mathrm{V}_{\mathrm{T}}\right)=\mathrm{q}^{\prime}
\end{aligned}
$$

then her new credence in $\mathrm{G}$ is: 


$$
\left.\mathrm{P}^{\prime}(\mathrm{G})=\mathrm{q}^{\prime} \times \mathrm{s}^{\prime}+\left(1-\mathrm{q}^{\prime}\right) \times \mathrm{r} \quad \text { (by Jeffrey conditionalization }\right)
$$

This decreases her credence in $\mathrm{G}$ iff the following inequality holds:

$$
\mathrm{q}^{\prime} \times \mathrm{s}^{\prime}+\left(1-\mathrm{q}^{\prime}\right) \times \mathrm{r}<\mathrm{q} \times \mathrm{s}+(1-\mathrm{q}) \times \mathrm{r}
$$

This is a general account of what it takes for this argument from evil to provide evidence against the existence of God to an agent. ${ }^{9}$ Note that it is consistent with the reduction in credence's being very small, and the posterior probability in G's being very high.

I will argue that each of the arguments from evil based on the four listed conditions on divine world creation, if cogent, is strengthened by evidence for noetism $(\mathrm{N})$. Because I am assuming the four arguments from evil are cogent, I am assuming (1) holds for each. In the case of the argument just reviewed:

$$
\mathrm{P}^{\prime}\left(\mathrm{V}_{\mathrm{T}}\right) \times \mathrm{P}^{\prime}\left(\mathrm{G} \mid \mathrm{V}_{\mathrm{T}}\right)+\left(1-\mathrm{P}^{\prime}\left(\mathrm{V}_{\mathrm{T}}\right)\right) \times \mathrm{P}\left(\mathrm{G} \mid \sim \mathrm{V}_{\mathrm{T}}\right)<\mathrm{P}\left(\mathrm{V}_{\mathrm{T}}\right) \times \mathrm{P}\left(\mathrm{G} \mid \mathrm{V}_{\mathrm{T}}\right)+\left(1-\mathrm{P}\left(\mathrm{V}_{\mathrm{T}}\right)\right) \times \mathrm{P}\left(\mathrm{G} \mid \sim \mathrm{V}_{\mathrm{T}}\right)
$$

For the threshold argument to be strengthened by evidence for $\mathrm{N}$ means that for two alternate posterior probability functions $\mathrm{P}^{\prime}$ and $\mathrm{P}^{*}$ that differ only in probabilities assigned to valueneutral evidence ${ }^{10}$ for $N$, where $\mathrm{P}^{*}(\mathrm{~N})>\mathrm{P}^{\prime}(\mathrm{N}), \mathrm{P}^{*}(\mathrm{G})<\mathrm{P}^{\prime}(\mathrm{G})$. In other words:

$$
\mathrm{P}^{*}\left(\mathrm{~V}_{\mathrm{T}}\right) \times \mathrm{P}^{*}\left(\mathrm{G} \mid \mathrm{V}_{\mathrm{T}}\right)+\left(1-\mathrm{P}^{*}\left(\mathrm{~V}_{\mathrm{T}}\right)\right) \times \mathrm{P}\left(\mathrm{G} \mid \sim \mathrm{V}_{\mathrm{T}}\right)<\mathrm{P}^{\prime}\left(\mathrm{V}_{\mathrm{T}}\right) \times \mathrm{P}^{\prime}\left(\mathrm{G} \mid \mathrm{V}_{\mathrm{T}}\right)+\left(1-\mathrm{P}^{\prime}\left(\mathrm{V}_{\mathrm{T}}\right)\right) \times
$$

\section{$\mathrm{P}\left(\mathrm{G} \mid \sim \mathrm{V}_{\mathrm{T}}\right)$}

My argument for (3) has two parts:

$$
\begin{aligned}
& \mathrm{P}^{*}\left(\mathrm{~V}_{\mathrm{T}}\right)>\mathrm{P}^{\prime}\left(\mathrm{V}_{\mathrm{T}}\right) \\
& \mathrm{P}^{*}\left(\mathrm{G} \mid \mathrm{V}_{\mathrm{T}}\right)=\mathrm{P}^{\prime}\left(\mathrm{G} \mid \mathrm{V}_{\mathrm{T}}\right)^{11}
\end{aligned}
$$

The assumption that the threshold argument is cogent implies $\mathrm{P}^{*}\left(\mathrm{G} \mid \mathrm{V}_{\mathrm{T}}\right)<\mathrm{P}\left(\mathrm{G} \mid \sim \mathrm{V}_{\mathrm{T}}\right)$ and $\mathrm{P}^{\prime}\left(\mathrm{G} \mid \mathrm{V}_{\mathrm{T}}\right)<\mathrm{P}\left(\mathrm{G} \mid \sim \mathrm{V}_{\mathrm{T}}\right)$. As some calculation reveals, these claims together with (4) and (5) entail (3). To defend (4), I argue that:

$$
\mathrm{P}\left(\mathrm{V}_{\mathrm{T}} \mid \mathrm{N}\right)>\mathrm{P}\left(\mathrm{V}_{\mathrm{T}} \mid \sim \mathrm{N}\right)
$$


To defend (5), I argue that:

$$
\mathrm{P}\left(\mathrm{G} \mid \mathrm{V}_{\mathrm{T}} \& \mathrm{~N}\right)=\mathrm{P}\left(\mathrm{G} \mid \mathrm{V}_{\mathrm{T}} \& \sim \mathrm{N}\right)
$$

If (6) and (7) hold, evidence for $\mathrm{N}$ will increase a rational agent's credence in $\mathrm{V}_{\mathrm{T}}$ without increasing her credence in $\mathrm{G}$ given $\mathrm{V}_{\mathrm{T}}$, relative to what it would have been had she not acquired that evidence for $\mathrm{N}$. Consequently, the agent will lower her credence in $\mathrm{G}$ relative to what it otherwise would have been. I now turn to defending (6) and (7) and their counterparts for each of the arguments from evil under consideration, beginning with (6).

\section{No gratuitous evil condition}

The argument from evil based on the no gratuitous evil condition centers on $\mathrm{V}_{\mathrm{NGE}}$, the claim that the no gratuitous evil condition is violated, i.e. that there is evil the permission of which is not necessary for a greater good or the prevention of a worse evil. The defence of a high $\mathrm{P}\left(\mathrm{V}_{\mathrm{NGE}}\right)$ usually takes the form of an inference from appearance to reality (Rowe (1979); (1984); (1996); (2006); Russell (1996)). William Rowe adduces several examples in which it seems there are evils that do not seem to lead to - much less be a necessary condition for - an overall improvement in the value of the universe. The most famous of these involves the suffering of a fawn, who unbeknownst to any humans, was burned in a forest fire and died after suffering for three days. Rowe's examples are supposed to evoke a large number of other instances of apparently gratuitous evil.: $\mathrm{A}_{1} \& \mathrm{~A}_{2} \ldots \mathrm{A}_{\mathrm{n}}$. Rowe argues that $\mathrm{P}\left(\mathrm{V}_{\mathrm{NGE}} \mid \mathrm{A}_{1} \& \mathrm{~A}_{2} \ldots \mathrm{A}_{n}\right)$ is high, and concludes $V_{\text {NGE }}$ is likely true. Since my conclusion is conditional, I must establish that, if Rowe's reasoning from appearance to reality is cogent, $\mathrm{P}\left(\mathrm{V}_{\mathrm{NGE}} \mid \mathrm{N}\right)>\mathrm{P}\left(\mathrm{V}_{\mathrm{NGE}} \mid \sim \mathrm{N}\right)$. The conditional nature of my conclusion allows me to prescind from the question of whether the 
inference from appearance to reality really is cogent (for arguments that it is not, see, e.g., Wykstra (1990); Plantinga (1996); Baggett (2006)).

The power of the list of apparently gratuitous evils depends on two qualities. First, the number of conjuncts is large. If there were only a few conjuncts, there might be a significant chance that the appearance of gratuitous evil could be explained away in these few cases. Because there are so many, it seems incredible that, in each case, there is a just-so story that explains how that instance of evil is not gratuitous.

Second, it is important that the appearance of gratuitousness is strong. Apparent gratuitousness comes in degrees. Here's a weak appearance of gratuitousness. I stub my toe and end up losing a toenail. This is painful yet doesn't result in any personal transformation on my part. It is hard to see how this toe-stubbing is a necessary condition for a greater good or the prevention of a worse evil. Yet this appearance is weak in that there are a number of factors which make it easier to think of an explanation for its being a non-gratuitous evil. For example, I know about it, and my friends know about it, and it has implications for my future activities, and it isn't that bad of an evil. The fawn example has a much stronger appearance of gratuitousness because no higher intelligence knows about it, it has no implications for the fawn's future activities, suffering and death are quite bad, and it looks causally very similar to the same case except where the fawn dies quickly.

Let's examine how evidence for $\mathrm{N}$ combined with Copernican reasoning affects the empirical premise of the argument from appearance to reality. To begin, it adds conjuncts. If noetism is true, we would be in an unlikely position in the universe if we were on the only planet on which there are apparently gratuitous evils (where 'apparently gratuitous' rigidly designates our perspective). Therefore, there are likely instances of apparently gratuitous evils on other 
inhabited planets. We cannot reach any conclusion about the strength of the appearance of the gratuitousness of these evils directly, because we have no details about the evils we thereby infer. We can infer that some of these evils are likely significantly worse than any evils on Earth, but that doesn't have any implications for their apparent gratuitousness. However, Copernican reasoning can be applied to the degree of apparent gratuitousness of these evils. It would be remarkable if our planet contained the evils that were the most apparently gratuitous in the universe. Therefore, there are likely planets on which there are evils that are more apparently gratuitous than some of the evils on our planet. ${ }^{12}$

Yet if the maximal or minimal possible degree of a value is already observed on Earth, Copernican reasoning will not work to extend the range of likely values in that direction. An example is minimum lifespan. Tragically, there are humans who die on the day they are born. We cannot use Copernican reasoning to infer that there are creatures whose shortest living members post-birth live significantly shorter lives than the shortest living humans post-birth, since the shortest living humans post-birth exemplify or are extremely close to the minimal possible degree of this value. Thus, establishing that Copernican reasoning allows us to infer that there are evils significantly more apparently gratuitous than the most apparently gratuitous evils on Earth requires an argument that we do not already observe the maximal possible degree of apparent gratuitousness on Earth.

It might seem that in fact we do observe a maximal degree of apparent gratuitousness on Earth. How much more apparently unconnected to potential greater goods could an evil be than the suffering of Rowe's fawn? But this degree of apparent gratuitousness is not maximal, for two reasons. First, on some views, it is better for conditions on Earth to improve over time, rather than simply to begin in a blessed state. If we assign any credence to such views, then the slope of 
the graph of value over time is relevant to our overall evaluation of the value of conditions on Earth. On many indicators, the quality of life for humans on Earth has improved dramatically over time, lending at least some plausibility to the idea that conditions on Earth are improving. For evils to be replaced by goods over time, it is necessary that there be evils in the first place. This is a potential justification of instances of suffering such as that of Rowe's fawn. But this justification is challenged by Copernican reasoning. If there are intelligent extraterrestrials, it is very likely that there are planets on which the graph of value over time has a lower slope than on Earth, decreasing the plausibility of the idea that conditions on every planet are improving over time.

The second reason that the degree of apparent gratuitousness of evils on Earth is not maximal is that the suffering of non-human animals on Earth is observed by, or else potentially inferred by, intelligent creatures. Rowe tries with his fawn example to come up with something causally isolated from humans. But we know that these kinds of things happen on Earth, and we have detailed information about the creatures that thereby suffer. We have not always known about the suffering of creatures prior to the evolution of humans, but now this knowledge is easily attained, at least among people who choose to avail themselves of it. If noetism is true, and, as is obvious, intelligent life does not evolve on every inhabited planet, then there are inhabited planets which never contain intelligent life. The suffering of creatures on these planets is more isolated from intelligence than even the suffering of creatures on Earth before humans evolved. Since reflections on Copernican reasoning will never achieve the level of widespread influence as knowledge of the biology of Earth before humans, and in any event intelligent creatures could not gain details about this suffering that might be spiritually instructive because of the vastness of interstellar space, there will be evils with higher degrees of apparent 
gratuitousness on these planets in the form of suffering that no finite intelligence will ever learn about.

I conclude that we do not observe a maximal level of gratuitous evil on Earth, and hence noetism plus Copernican reasoning licenses an inference to the likely existence of greater degrees of gratuitous evil than we have heretofore observed. Evidence for $\mathrm{N}$ is thus evidence for conjuncts that have a higher degree of apparent gratuitousness than any evils on Earth, as well as a higher overall number of conjuncts in $A_{1} \& A_{2} \ldots A_{n}$. If the reasoning from appearance to reality is cogent, the argument from evil based on gratuitous evils is strengthened by evidence for N.

It may be objected that, while this is correct, the effect is going to be absolutely trivial. ${ }^{13}$ There are so many conjuncts already in $A_{1} \& A_{2} \ldots A_{n}$, some of which have high degrees of apparently gratuitous evil, that the addition of more conjuncts, some with a greater degree of apparent gratuitousness, is going to have a miniscule effect on the resulting credence in $\mathrm{V}_{\mathrm{NGE}}$ (assuming the argument from appearance to reality is cogent to begin with).

This observation about the effect size is certainly true mathematically. Whether it is a problem for my conclusion relates to the intended audience of arguments from evil; I discuss this below ('The overkill objection'). For now, I emphasize that, as far as this objection goes, the claim that $\mathrm{P}\left(\mathrm{V}_{\mathrm{NGE}} \mid \mathrm{N}\right)>\mathrm{P}\left(\mathrm{V}_{\mathrm{NGE}} \mid \sim \mathrm{N}\right)$ is correct.

\section{Weak patient-centred condition}

The argument from evil based on the weak patient-centred condition defends VwPC, the claim that the weak patient-centred condition is violated, i.e. that there is an individual whose life is not worth living. It does so by appeal to examples of lives that do not seem worth living. These 
will be lives that contain great evils and few goods. Another inference from appearance to reality is then made to the conclusion that V WPC is likely true. As with the argument for $\mathrm{V}_{\mathrm{NGE}}$ from the previous section, the strength of the argument for VwPC is going to depend on how many lives there are that do not seem worth living, and the degree to which they do not seem worth living. And as we have seen, evidence for $\mathrm{N}$ will also be evidence for the claim that there are more lives that do not seem worth living, and that some of these lives are very likely much worse than the worst lives on Earth. It follows that evidence for $\mathrm{N}$ is evidence for VwPC. On the assumption that the argument for $\mathrm{V}_{\text {WPC }}$ is cogent to begin with, $\mathrm{P}\left(\mathrm{V}_{\mathrm{WPC}} \mid \mathrm{N}\right)>\mathrm{P}\left(\mathrm{V}_{\mathrm{WPC}} \mid \sim \mathrm{N}\right)$.

One objection to this argument is that we cannot infer from any balance of goods and evil that we observe in a life, that this life is likely not worth living, because however much this balance is weighted towards evils, this amount will be finite, and can be outweighed by goods provided in an infinite afterlife (Tracy (1992)). ${ }^{14}$ If this objection is sound, then discovering that there are likely creatures on other planets who experience even more evils and fewer goods than the most miserable creatures on Earth will not matter at all, because any finite amount of evil can be washed away by infinite blessedness.

I have two responses to this objection. First, my thesis is conditional: it only claims that the arguments I'm discussing, if cogent in the first place, are strengthened by evidence for N. The afterlife objection, if it lands, undermines the cogency of this argument from evil. Second, the proper response to the afterlife objection by the atheologian illuminates the way that evidence for $\mathrm{N}$ strengthens this argument from evil.

The proper response to the afterlife objection is to observe that it reflects a misguided approach to thinking about value in the context of infinity. It is true that ordinal arithmetic allows any finite sum to be washed out by the addition of an infinite number. If the value of a life is the 
aggregation of the value of its parts, as the afterlife objection seems to assume, ${ }^{15}$ and if value aggregation can be modeled by ordinal arithmetic, then we indeed get the result that a creature's earthly suffering is irrelevant to the overall value of its life when it enjoys an infinite, blissful afterlife. However, as Peter Vallentyne and Shelly Kagan have argued (Vallentyne \& Kagan (1997)), ordinal arithmetic is not a good model for value aggregation in infinite contexts. We can make meaningful value distinctions among sources of infinite aggregated value with the same cardinality. For example, we prefer eternal life with 2 Standard Goodness Units (SGUs) per day over eternal life with $1 \mathrm{SGU/day,} \mathrm{even} \mathrm{though} \mathrm{when} \mathrm{aggregated,} \mathrm{they} \mathrm{both} \mathrm{have} \mathrm{value} \omega$. Similarly, we would strongly prefer an afterlife with one day of moderate suffering followed by eternal blessedness over an afterlife with 10 trillion years of extreme suffering followed by eternal blessedness, even though both have aggregated value $\omega .{ }^{16}$ Assuming that our preferences here reflect reality, values in infinite situations cannot be identified with aggregate value as modeled by ordinal arithmetic. (Vallentyn and Kagan have devised principles for ranking the value of different sorts of cases; there is not space to go into the details here, but their analysis bears out the intuitions I endorse.)

Recognizing that locations of infinite value with the same cardinality can differ in value opens the door for making distinctions among packages of finite evil combined with infinite bliss. In particular, it raises the possibility that there are some packages in which finite suffering is redeemed by eternal bliss (the afterlife with one day of moderate suffering), and some in which it is not (the afterlife with 10 trillion years of extreme suffering). It certainly seems to me that it would be better simply to cease to exist, rather than to experience the latter kind of afterlife. ${ }^{17}$ 
Now the case we are considering is importantly different from this thought experiment in two ways: (1) the finite evils are part of an earthly life rather than a finite part of an infinite afterlife; and (2) the alternative to the package of finite evil plus eternal bliss is not ceasing to exist, but rather not coming into existence in the first place. Difference (2) does not seem to threaten my response to the afterlife objection. Although it might seem paternalistic for we, the existing, to make judgements about whether it is worth it for potential beings to come into existence in order to live certain kinds of lives, our intuitions about afterlife packages are in fact a suitable proxy for judgements about life plus afterlife packages. If we have an intuition that the finite suffering in a particular afterlife package is not worth the subsequent infinite bliss, that intuition should hold for a life plus afterlife package with the same amount of suffering and bliss from the perspective of a potential person. If anything, the intuition that a particular form of afterlife isn't worth it is an overestimate of the proper judgement about the corresponding life plus afterlife package, on the assumption that going out of existence harms us (Nagel (1970)). If we prefer nonexistence, which involves for us the harm of ceasing to exist, over a certain package of finite evils and eternal bliss, then it follows that we would prefer nonexistence simpliciter - which would not have harmed us (Robert Adams (1972), 319; Parfit (1984)) - to this package.

Difference (1) is connected with the reason why the atheologian's reply to the afterlife objection is made more plausible by evidence for $\mathrm{N}$. In the above example, I reference an afterlife package that includes 10 trillion years of intense suffering in my attempt to elicit the intuition I want the reader to have. But what we are really considering is whether all earthly lives that do not seem worth living can be redeemed by an infinite afterlife. The earthly life of humans is limited to about 120 years, and realistically speaking, any life that does not seem worth living 
will almost certainly be significantly shorter than that. Thus our biological limitations protect us from suffering all that long. So it might be argued that, while 10 trillion years of extreme suffering would not be an acceptable price for infinite bliss, a maximum of 120 years of extreme suffering would be, and so we cannot infer from earthly lives that do not seem worth living, that they are likely not worth living.

The atheologian is trying to push the intuition that severe, finite torment might not be worth infinite bliss: given a miserable existence of, say, 80 years, plus eternal bliss, better not to have been born at all. Whatever degree of plausibility this argument has, it will be more plausible given $\mathrm{N}$. If there are intelligent extraterrestrials, there will almost certainly be those with longer lifespans than us, with a greater capacity to endure more severe physical and psychological pain, and who are unluckier in their circumstances. (It is unlikely that we are the creatures with the greatest capacity to suffer, and greatest actual suffering, in the universe!) The appearance of a life not worth living will be stronger on the assumption of $\mathrm{N}$ than on $\sim \mathrm{N}$, and so evidence for $\mathrm{N}$ confirms VwPC (assuming the appearance to reality inference is cogent in the first place).

\section{Strong patient-centred condition}

Suppose it is true that the finite lifespans of biological beings do not allow for the accrual of the amount of misery necessary to make an afterlife of eternal bliss not worth the trouble. The atheologian is not out of options, as it can be maintained that what matters isn't whether a miserable person lives a life that is worth living, but whether that person lives a life that is the best that she could lead (cf. Tracy (1992), 318-319). The Vallentyne-Kagan result is then used to contend that there is a difference between the life a miserable person with an infinitely blissful 
afterlife actually leads and what she could have led. This leads directly to the argument from evil based on the strong patient condition.

The argument from evil based on the strong patient-centred condition defends the claim $V_{\text {SPC }}$ : the strong patient-centred condition is violated because there is evil suffered by an individual that is not part of the best available means for the overall improvement of her life. The argument for a high $\mathrm{P}^{\prime}\left(\mathrm{V}_{\mathrm{SPC}}\right)$ is going to resemble the argument for a high $\mathrm{P}^{\prime}\left(\mathrm{V}_{\mathrm{NGE}}\right)$. Both arguments have the conclusion that a particular evil is gratuitous. In the first case, it is gratuitous vis-à-vis the overall value of the universe. A comparison is made to the way the universe would be without that particular evil. In the second case, it is gratuitous vis-à-vis the value of a particular life. A comparison is made to the way that life would be without that particular evil. In both cases, there is an inference from appearance to reality. Consider a person who leads a particularly miserable earthly life. Assume that their life is composed of this misery plus an eternally blissful afterlife. It seems that this life would not be as good as the same afterlife preceded by less misery. It might be argued that for each piece of misery in their life, that piece of misery is essential for fulfillment in some sense - soul-making (Hick (1990)), the ability to fully enjoy the afterlife, the ability to engage fully in a relationship with God. The more instances of misery there are in a person's life, and the greater these miseries, the less plausible it is that there is a 'just so story' that explains why that person had to experience exactly this degree of misery in order to have a maximally fulfilling afterlife, especially given that others did not have to experience such misery. Since evidence for $\mathrm{N}$ is evidence for more individuals with more and greater miseries in their lives, evidence for $\mathrm{N}$ is evidence for $\mathrm{V}_{\mathrm{SPC}}$, on the assumption that the inference from appearance to reality is cogent in the first place. 
Since the argument here is similar to the argument above ('No gratuitous evil condition'), it will be vulnerable to the same objection, viz. that there is no appreciable gain in confirmation of $\sim \mathrm{G}$ when gaining evidence for $\mathrm{N}$. I discuss this objection at greater length below ('The overkill objection').

\section{Threshold condition}

The argument from evil based on the threshold condition defends $\mathrm{V}_{\mathrm{T}}$ by adducing evils that seem clearly to be beyond the relevant threshold, the most evocative example being the speech by Ivan Karamazov (Dostoevsky (1990); see the analysis in Cohen (2013)). Ivan asks Alyosha whether he would accept a ticket for universal justice and harmony for the price of the individual instances of horrific suffering he adduces; Alyosha declines. Because we are not able to say exactly when an evil is so horrific that no good could justify its permission, this kind of appeal to intuition is made more plausible the worse the suffering adduced. Copernican reasoning tells us that evidence for noetism is evidence for there being evils significantly worse than the worst evils on Earth. I conclude that if the threshold argument is cogent in the first place, $\mathrm{P}\left(\mathrm{V}_{\mathrm{T}} \mid \mathrm{N}\right)>\mathrm{P}\left(\mathrm{V}_{\mathrm{T}} \mid \sim \mathrm{N}\right)$.

\section{The independence claim}

In order to establish that these four arguments from evil are strengthened by evidence for $\mathrm{N}$, I also need to defend claims such as (7): $\mathrm{P}\left(\mathrm{G} \mid \mathrm{V}_{\mathrm{T}} \& \mathrm{~N}\right)=\mathrm{P}\left(\mathrm{G} \mid \mathrm{V}_{T} \& \sim \mathrm{N}\right)$. (7) means that on the condition that the threshold condition on divine world creation is violated, the claims that a perfect God exists and that intelligent extraterrestrial life exists are independent. If all we consider is the threshold argument, this seems correct: the only effect the probability of $\mathrm{N}$ has on 
the probability of $\mathrm{G}$ is via providing evidence for $\mathrm{V}_{\mathrm{T}}$, so on the condition that $\mathrm{V}_{\mathrm{T}}$ is true, whether God exists is probabilistically independent of the truth of N.

However, things are more complicated if an agent endorses more than one of the arguments from evil as well as the conclusion of this paper. If so, she is not going to think that $\mathrm{P}\left(\mathrm{G} \mid \mathrm{V}_{\mathrm{T}} \& \mathrm{~N}\right)=\mathrm{P}\left(\mathrm{G} \mid \mathrm{V}_{\mathrm{T}} \& \sim \mathrm{N}\right)$, because $\mathrm{N}$ also provides evidence for $\mathrm{V}_{\mathrm{NGE}}, \mathrm{V}_{\mathrm{SPC}}$, and $\mathrm{V}_{\mathrm{WPC}}$, which in turn provide evidence against G. However, in this case, she is going to think that $\mathrm{P}\left(\mathrm{G} \mid \mathrm{V}_{\mathrm{T}} \& \mathrm{~N}\right) \leq \mathrm{P}\left(\mathrm{G} \mid \mathrm{V}_{\mathrm{T}} \& \sim \mathrm{N}\right)$. This in turn implies:

$$
\mathrm{P}^{*}\left(\mathrm{G} \mid \mathrm{V}_{\mathrm{T}}\right) \leq \mathrm{P}^{\prime}\left(\mathrm{G} \mid \mathrm{V}_{\mathrm{T}}\right)
$$

$\left(5^{*}\right)$ and (4), combined with the assumption that the threshold argument is cogent, entail (3), the main claim of the paper.

Some may argue that if we take this broader perspective on what is confirmed by $\mathrm{N}$, we need to consider also the argument that evidence for $\mathrm{N}$ is evidence for $\mathrm{G}$ because God would create more intelligence rather than less. Arguably, this consideration in favour of G could overwhelm the confirmational boost provided to $\sim \mathrm{G}$ by asymmetrical arguments from evil. This approach is referenced below ('A Moorean shift', 'Conclusion'); comprehensive discussion is reserved for future work.

\section{Objections and replies}

Evils are not evidence against the existence of God

Recently, some have claimed that not only do the evils of the world fail to give sufficient justification for the claim that God does not exist, they fail to constitute any evidence whatsoever against God's existence. While my thesis is conditional on the cogency of the arguments from evil that I have discussed, and so is technically not threatened by the claim that these arguments 
from evil do not provide any evidence against the existence of God, I want to say something about this claim, because if it is correct, my conclusion is less interesting.

In the present framework, this claim can manifest in two ways. First, it can be used to attack the condition on which an argument from evil is based. For example, it can attack the claim that a perfect God would not allow gratuitous evil, as in van Inwagen's no minimum defence (van Inwagen (2006)). This reply grants the confirmational relationships argued for above ('Asymmetrical arguments from evil'), but denies that this has any consequences for $\mathrm{P}^{\prime}(\mathrm{G})$ because the premise stating the relevant condition is false. For example, $P\left(G \mid V_{N G E}\right)=P(G)$; hence evidence for $\mathrm{V}_{\text {NGE }}$ does not result in a lower $\mathrm{P}^{\prime}(\mathrm{G})$ (Plantinga (1996), 76). Second, it can attack the existence of apparent gratuitous evils or the inference from apparent gratuitous evils to actual gratuitous evils, as in sceptical theism (Wykstra (1990); (1996); Alston (1996)).

While space does not allow a detailed consideration of these arguments, there is a significant challenge that they face. If these responses to arguments from evil are correct, then not only would a sheltered child learning about horrible events in world history for the first time not thereby gain any evidence against the existence of God, but a sheltered child learning about horrible events in the history of a world much, much worse than ours would not thereby gain any evidence against the existence of God. In fact, it would seem that on these views there is no limit to how bad a world could be without its badness counting as evidence against the existence of God (McGrath (1992), 61; Cohen (2013), 82-83). But, pace Wykstra ((1990), 158-160), this is just absurd. Thus learning about evils can be evidence against the existence of God (Gale (1996), 214).

A Moorean shift 
It has been observed that probabilistic versions of the argument from evil must consider the possibility of positive evidence for the existence of God (Plantinga (1979), 3). In the present case, it could be argued that strong evidence that God exists combined with the endorsement of some necessary conditions on divine world creation would undermine the ignorance required for Copernican reasoning because it would give us a constraint on how bad things could get in the universe.

My first reply is that this maneuver cannot be employed by sceptical theists, or by those just discussed who claim that evils are not evidence against the existence of God. These thinkers embrace a radical scepticism about what we can infer regarding evil on the assumption that God exists. This means that evidence for the existence of God does not give us any information about evil in the universe, and so does not undermine our ignorance and block Copernican reasoning.

For theists who think that evidence for the existence of God gives us information about the extent of evil in the universe, I accept the point. Copernican reasoning is only operative in the absence of other information. For these theists, on the confirmational relationships for which I have argued, evidence that God exists confirms the following disjunction: noetism is false or there are humans among the worst-off creatures in the whole universe. Someone with strong evidence that God exists who subsequently received evidence for noetism would then have evidence that we do indeed occupy an unlikely place in the universe: a planet where some of the worst things ever have happened. This would prevent Copernican reasoning from strengthening the arguments from evil discussed in this paper.

All of this is interesting in itself. Moreover, it does not vitiate the relevance of the claims of this paper to the debate about the problem of evil. Van Inwagen (2006) connects the success of arguments from evil in principle to the reactions of ideal agnostics (while he remains sceptical 
that these or indeed any philosophical arguments can be truly successful). Ideal agnostics do not take themselves to have strong evidence that God exists, so for them, Copernican reasoning, and the arguments of this paper, are in force.

\section{The overkill objection}

As discussed above ('No gratuitous evil condition', 'Weak patient-centred condition'), the objection might be made that the evils we know about on Earth are so great and numerous, that the case against a perfect being's existence is not made stronger in any significant way by pointing to the likely existence of worse evils. Or, to put it the other way round, any defence against the problem of evil that is satisfactory for the grotesque Earthly evils we know about will be able to handle evils that, while worse, may be roughly of the same order of magnitude.

I have several lines of response to this objection. The first was already presented ('No gratuitous evil condition'): mathematically, there must be an increase in the confirmation of $\sim \mathrm{G}$, even if this increase is quite small. (A comparison might be made here to the Bayesian analysis of the raven paradox: the observation of non-black non-ravens does confirm that all ravens are black, just not by very much.) This means that, technically, the thesis of the paper is correct.

Second, if we think the goal of arguments of evil is to convince thoughtful agnostics, the intended audience of these arguments is not already overwhelmed by the evidence provided by Earthly evils. It may be that consideration of worse evils is enough to sway them. On the other

hand, some thoughtful agnostics may be completely persuaded by a defence against the problem of evil, and be agnostic because of the absence of evidence for the existence of God. For such agnostics, the defence they accept against arguments from evil may suffice to cover the likely existence of worse evils implied by Copernican reasoning and evidence for noetism. Yet while 
not all agnostic profiles find the results of this paper relevant, at least some do, and this makes it significant for the overall debate concerning arguments from evil.

Third, the result is at least of historical interest. Copernican reasoning also applies to learning that there is more intelligent life on Earth. ${ }^{18}$ There have been numerous times when some humans discovered that there were many more people than they had thought there were in the world. Some of these discoveries were made by people who knew less than we do about the severity of evils on Earth (in some cases, because they were not aware that they themselves were perpetrating horrible things against the people whose existence they were learning about). Thus, some of these people may have been in an evidential situation in which the contribution of Copernican reasoning combined with their learning of a greater population of persons would have made a significant difference to their assessments of the arguments of evil I have discussed, should they have considered all of this.

\section{Conclusion}

Evidence that there are more intelligent creatures in the universe strengthens asymmetrical arguments against the existence of God. When hunter-gatherer tribes previously uncontacted by other humans learn that there are many more humans than they supposed, asymmetrical arguments from evil are strengthened for them; so too for us, should we discover evidence of intelligent extraterrestrials. This is a surprising result: the more intelligent creation there is, the less likely a perfect God.

Some may argue this result is so surprising that it is in fact a reductio of asymmetrical arguments from evil. This would be a novel way to critique these arguments. If these arguments 
are cogent, then the bare discovery of more intelligent creatures provides evidence against the existence of God. But this is absurd; therefore, these arguments are not cogent.

I am unsure myself as to whether such a reductio would be successful. It will be hard to tease out the complexities of the intuition regarding the supposed absurdity. When we learn that there are more people than we thought in the universe, we thereby learn that there are a lot of good things. According to asymmetrical arguments from evil, this good doesn't balance off the evil: all that matters is that the bottom end of the range is expanded. But the defender of an asymmetrical argument from evil might contend that the intuition fueling the reductio is a confusion caused by aggregate thinking about value - we are led by the appeal of all that good to ignore something that is not properly ignored. Ajudicating this debate would require detailed investigation into the provenance of the intuition fueling the reductio and its connection to theories of aggregate value.

My main contention in this paper is that in thinking about arguments from evil, we need to consider evil throughout the whole universe as well as during past and future times. If Copernican reasoning is correct, then whether intelligent life exists on other planets has significant implications for how bad things get in the universe. This is especially salient as we are developing the ability to observe the atmospheric compositions of Earth-like exoplanets and look for microscopic life in habitable zones in our own solar system outside of Earth. This will give us much better evidence than we now have about the frequency of the development of life on habitable planets. If life develops frequently on habitable planets, there will likely be many intelligent extraterrestrials in the universe, and almost certainly, greater horrors and goods than those we already know about. If asymmetrical arguments from evil are cogent, we are on the 
brink of scientific discoveries that will have important implications for the evidential status of theism. 1920

\section{References}

ADAMS, MARILYN MCCORD (1999) Horrendous Evils and the Goodness of God (Ithaca NY: Cornell University Press).

ADAMS, ROBERT (1972) 'Must God create the best?', The Philosophical Review, 81, 317332.

ALSTON, WILLIAM (1996) 'The inductive argument from evil and the human cognitive condition' in D. Howard-Snyder (ed.) The Evidential Argument from Evil (Bloomington IN: Indiana University Press), 97-125.

BAGGETT, DAVID (2006) 'Bruce Russell's analogy and the evidential problem of evil', Philosophia Christi, 8, 463-473.

CARTER, BRANDON (1983) 'The anthropic principle and its implications for biological evolution', Philosophical Transactions of the Royal Society of London, A 310, 347-363.

CHISHOLM, RODERICK (1990) 'The defeat of good and evil', in M. M. Adams and R. M. Adams (eds) The Problem of Evil (Oxford: Oxford University Press), 53-68.

COHEN, YISHAI (2013) 'Skeptical theism and the threshold problem', Forum Philosophicum, $18,73-92$.

DOSTOEVSKY, FYODOR (1990) The Brothers Karamazov Trans. R. Pevear \& L. Volokhonsky (New York: Farrar, Straus and Giroux).

DRAPER, PAUL (2004) 'Cosmic fine-tuning and terrestrial suffering: Parallel problems of naturalism and theism', American Philosophical Quarterly, 41, 311-321. 
GALE, RICHARD M. (1996) 'Some difficulties in theistic treatments of evil', in D. HowardSnyder (ed.) The Evidential Argument from Evil (Bloomington IN: Indiana University Press), 206-218.

GOTT, J. RICHARD (1993) 'Implications of the Copernican Principle for our future prospects', Nature, 363, 315-319.

(1994) 'Future prospects discussed', Nature, 368, 108.

(1996) 'Our future in the universe', in V. Trimble and A. Reisenegger (eds) Clusters, Lensing, and the Future of the Universe (San Francisco: Astronomical Society of the Pacific), 140-151.

(2001) Time Travel in Einstein's Universe (Boston: Houghton Mifflin).

HASKER, WILLIAM (1992) 'The Necessity of Gratuitous Evil', Faith and Philosophy, 9, 2344.

HICK, JOHN (1990) 'Soul-making and suffering', in M. M. Adams and R. M. Adams (eds) The Problem of Evil (Oxford: Oxford University Press), 168-188.

JEFFREYS, HAROLD (1939) Theory of Probability (Oxford: Oxford University Press).

KRAAY, KLAAS J. (2013) 'Megill’s multiverse meta-argument', International Journal for Philosophy of Religion, 73, 235-241.

LESLIE, JOHN (1990) 'Is the end of the world nigh?', The Philosophical Quarterly, 40, 65-72. LEWIS, DAVID (2001) 'Survival and identity', in M. Loux (ed.) Metaphysics: Contemporary Readings (London: Routledge), 395-419.

MCGRATH, P. J. (1992) 'Is the problem of evil misconceived?', Religious Studies, 28, 61-64. MONTON, BRADLEY (2010) 'Against multiverse theodicies’, Philo, 13, 113-135. 
MONTON, BRADLEY \& KIERLAND, BRIAN (2006) 'How to predict future duration from present age', The Philosophical Quarterly, 56, 16-38.

NAGEL, THOMAS (1970) 'Death', Nous, 4, 73-80.

NASA (2014) ‘TESS: Transiting Exoplanet Survey Satellite’ (Online) https://tess.gsfc.nasa.gov/documents/TESS_FactSheet_Oct2014.pdf. Accessed 3rd August 2016.

(2015) 'James Webb Space Telescope-The science mission’ (Online) http://jwst.nasa.gov/resources/2015JWSTlitho.pdf. Accessed 3rd August 2016.

PARFIT, DEREK (1984) Reasons and Persons (Oxford: Oxford University Press).

PLANTINGA, ALVIN (1977) God, Freedom, and Evil, 2nd edn (Grand Rapids MI: William B. Eerdmans).

(1979) 'The probabilistic argument from evil', Philosophical Studies, 35, 1-53. (1996) 'Epistemic probability and evil', in D. Howard-Snyder (ed.) The Evidential Argument from Evil (Bloomington IN: Indiana University Press), 69-96.

ROWE, WILLIAM (1979) 'The problem of evil and some varieties of atheism', American Philosophical Quarterly, 16, 335-341.

(1984) 'Evil and the theistic hypothesis: A response to Wykstra', International Journal for Philosophy of Religion, 16, 95-100.

(1996) 'The evidential argument from evil: A second look', in D. Howard-Snyder (ed.) The Evidential Argument from Evil (Bloomington IN: Indiana University Press), 262285).

(2006) 'Friendly atheism, skeptical theism, and the problem of evil', International Journal for Philosophy of Religion, 59, 79-92. 
RUSSELL, BRUCE (1996) 'Defenseless', in D. Howard-Snyder (ed.) The Evidential Argument from Evil (Bloomington IN: Indiana University Press), 193-205.

SIMPSON, FERGUS (2016) 'The size distribution of inhabited planets', Monthly Notices of the Royal Astronomical Society, http://arxiv.org/abs/1503.07804. Accessed 25th February 2016.

STUMP, ELEANORE (1985) 'The problem of evil', Faith and Philosophy, 2, 392-423. (2010). Wandering in Darkness: Narrative and the Problem of Suffering (Oxford: Clarendon Press).

SWINBURNE, RICHARD (1998) Providence and the Problem of Evil (Oxford: Clarendon Press).

TRACY, THOMAS F. (1992) 'Victimization and the problem of evil: A response to Ivan Karamazov', Faith and Philosophy, 9, 301-319.

TRAKAKIS, NICK (2008) 'Theodicy: The solution to the problem of evil, or part of the problem?', Sophia, 47, 161-191.

VALLENTYNE, PETER, \& KAGAN, SHELLY (1997) 'Infinite value and finitely additive value theory', The Journal of Philosophy, 94, 5-26.

VAN INWAGEN, PETER (1996) 'The problem of evil, the problem of air, and the problem of silence', in D. Howard-Snyder (ed.) The Evidential Argument from Evil (Bloomington IN: Indiana University Press), 151-175. (2006) The Problem of Evil. (Oxford: Oxford University Press).

VELLEMAN, DAVID (2015) Beyond Price: Essays on Birth and Death. (Cambridge, UK: Open Book Publishers). 
WYKSTRA, STEPHEN J. (1990) 'The Humean obstacle to evidential arguments from suffering:

On avoiding the evils of "appearance", in M. M. Adams and R. M. Adams (eds) The

Problem of Evil (Oxford: Oxford University Press), 138-160.

(1996) 'Rowe's noseeum arguments from evil', in D. Howard-Snyder (ed.) The

Evidential Argument from Evil (Bloomington IN: Indiana University Press), 126-150.

ZAGZEBSKI, LINDA (1996) 'An agent-based approach to the problem of evil', International

Journal for Philosophy of Religion, 39, 127-139.

Notes

\footnotetext{
${ }^{1}$ Because Gott is assuming an even probability distribution for our existence throughout the lifespan of humanity, the probability, e.g., that we are in the second half of the lifespan of humanity is .5 as well. The results generated by dividing up the interval in different ways are all consistent.

${ }^{2}$ Brandon Carter (1993) and John Leslie (1990) defend the Doomsday argument against the extreme longevity of the human species. The Doomsday argument differs from Gott's application of Copernican reasoning because: (1) it does not use the Jeffreys prior (see below); (2) it operates based on birth order rather than the time since the evolution of modern humans; and (3) it contends we should always shift our prior probability of human extinction - whatever it may be - earlier, whereas Gott's prediction shifts it later if we are initially pessimistic.

${ }^{3}$ If the universe is infinitely large, and there are an infinite number of intelligent extraterrestrials, a technical issue arises with Copernican reasoning because there cannot be a measure over an infinite population. This can be solved by engaging in Copernican reasoning about an extremely large finite sphere of space centred around Earth, thus allowing a measure.

${ }^{4}$ By Copernican reasoning, if noetism is true, it would be unlikely that we are the only intelligent species capable of suffering or experiencing evil, unless these concepts are essentially linked to our evolutionary history. Since I do not have space to explore, e.g., type physicalism or moral relativism, I assume throughout that intelligent extraterrestrials, should they exist, are able to suffer and experience evil.

${ }^{5}$ It might be argued that intelligence is inversely related to the experience of evil, because beings with greater intelligence would use natural resources more prudently, avoid conflict, etc. If intelligence is correlated with population size, this threatens my claim that planets with greater populations than Earth's would likely contain greater evils than Earth. Now, there is some reason to think intelligence does not correlate with population size, because if humans were more intelligent, we would not have created such a resource-intensive civilization. But even if
} 
intelligence does correlate with population size, the conclusion of this paragraph - that there is a strong Gott-like shift towards thinking that our local maximum of evil is not the global maximum - seems reasonable, because larger populations allow for larger calamities, and it would be remarkable if we had just enough population, but not enough intelligence, to witness the greatest evils in the universe. I am grateful to the anonymous referee who raised this point, which will be important to consider in a full-scale analysis of the relationship between greaterthan-typical population size and value.

6 There is a sense in which an argument from evil based on aggregate value might be affected by evidence for noetism. Say that I am confident that the only intelligent life in the universe is on Earth, and that the aggregate value on Earth lies below the threshold of divine world creation. If I then gain evidence for noetism, I don't thereby change my prevision of aggregate value in the universe. However, I do expand my sense of the possible variance from my prevision. Thus, for some people, evidence for noetism reduces the power of this argument from evil, because it increases the chance that there is greater good hiding elsewhere in the universe. The effect works the other way, too. Someone might be confident that value on Earth exceeds the given threshold; then, gaining evidence for noetism would diminish their confidence, because there are more places for evil to be hiding in the universe, and it could turn out that Earth is an uncharacteristic sample. But while this effect may be asymmetrical for a particular person, it remains symmetrical in the sense that for every epistemic profile for which it strengthens the aggregate version of the problem of evil, there is a profile for which it weakens it. The asymmetrical arguments which I will discuss are strengthened by evidence for noetism for every epistemic profile that regards them as cogent.

${ }^{7}$ Some theists endorse necessary conditions on divine world creation in their attempt to present justifying reasons for God's permission of certain sorts of evil. Hence the citations below do not entail that the authors subscribe to the arguments from evil associated with the particular necessary conditions on divine world creation that they endorse.

${ }^{8}$ Reducing one's credence in $\mathrm{P}\left(\mathrm{G} \mid \sim \mathrm{V}_{\mathrm{T}}\right)$ would do the trick as well, but that would not be motivated by the argument from evil based on the threshold condition.

${ }^{9}$ This account of evidence faces the problem of old evidence. If someone is already convinced that God does not exist, reflection on a new argument from evil will not serve as evidence for them against the existence of God on my account, even though intuitively, such an argument, if cogent, would be confirming evidence for their belief. I prescind from this issue here. If the problem of old evidence cannot be solved, my approach to modeling arguments from evil will have to be substantially overhauled in any case.

10 The evidence's being value-neutral means it itself can't have immediate and obvious negative or positive consequences for humanity (see note 18).

${ }^{11}$ Phrasing this as an equality results in some complications. These are discussed below ('The independence condition').

${ }^{12}$ A different route to this conclusion might be attempted: it is likely there are intelligent extraterrestrials who are not as intelligent as us; for these creatures, there would be a stronger appearance of gratuitous evil (non-rigidly designated), because they would not be as adept as we are at positing possible justifying reasons for them. A possible problem with this approach is that it doesn't seem that we should be concerned about the apparent gratuitousness of evils from the perspective of our intellectual inferiors. Indeed, sceptical theists typically respond to Rowe's argument by pointing to our own limitations in determining the justifying reasons for various 
evils. They might attempt to argue that by Copernican reasoning, there are likely intelligent extraterrestrials who are significantly smarter than us - and these creatures would not be motivated by the appearance of gratuitous suffering to us. However, I don't think this follows. They might turn out to be so motivated, just as they would be convinced by Gödel's proofs. I would like to thank an anonymous referee for raising this evocative issue.

${ }^{13} \mathrm{I}$ am grateful to an anonymous referee for raising this point.

${ }^{14} \mathrm{I}$ am grateful to an anonymous referee for raising this objection.

15 There are ways this objection might avoid making this assumption. For example, it might be thought that the order of positive and negative value in a person's life is relevant (Velleman (2015), 141-175), and thus that the closeness to God in an afterlife allows for redemption of earthly suffering in the way that it couldn't if, per impossible, the earthly life happened afterwards. Space does not allow pursuit of alternatives to value aggregation, but I believe the main intuitions I defend in what follows will still hold on such alternatives.

${ }^{16}$ It might be objected that no one could retain their personal identity through millennia of torture, and that the offer of an afterlife only makes sense if personal identity is retained. I agree. This is why I hold that hell as traditionally described is metaphysically impossible. So please substitute this scenario with the time frame and level of torture to be the maximal you think a person can withstand while retaining identity.

Some philosophers hold that, even with no torture, there is a limit to how long a person can retain identity (Parfit (1984); Lewis (2001)). If this is true, the strategy of appealing to an infinite afterlife to avoid this version of the argument from evil is not going to work anyway. ${ }^{17}$ Another way to put this point is that if we allow an infinite afterlife to wash away all earthly suffering, then no amount of earthly suffering in the life of a creature would count as any evidence against the existence of God. But this seems absurd, especially if we are granting a low $\mathrm{P}\left(\mathrm{G} \mid \mathrm{V}_{\mathrm{WPC}}\right)$. Later, I will discuss a similar failing in some recent objections to arguments from evil.

${ }^{18}$ Copernican reasoning only functions in the absence of information. We can imagine that in certain circumstances getting information related to the existence of other intelligent beings in the universe would bring with it other information relevant to our assessment of value in the universe (we infer their existence because we see their photon torpedoes headed our way), but in the most likely case, we will get evidence regarding their existence without any value-laden information (we detect atmospheric biomarkers on an exoplanet). Copernican reasoning is less likely to apply to learning that there will be many more humans than you had previously thought there would be, because learning that there will be more humans is often not value-neutral. For example, Alexander Fleming, the discoverer of penicillin, had the experience of discovering that there would be many more humans than he had previously thought there would be, but at the same time he learned that their lives would be significantly better (they would lose fewer loved ones to infection and would be less likely to be harmed by infection themselves).

${ }^{19}$ Some physicists have hypothesized that the actual world is a multiverse. Evidence for this hypothesis would be ipso facto evidence for the existence of abundant intelligent extraterrestrial life, and so, by the argument of this paper, would strengthen the four discussed arguments against the existence of God. For this reason and others, Copernican reasoning seems to undermine attempts to develop a multiverse theodicy. I explore this issue in (reference withheld). ${ }^{20}$ I would like to thank all of the people have been so generous with their time and intelligence in helping me think through these issues: Nathan Anderson, Dawn Eschenauer Chow, Dustin 
Crummett, Finnur Dellsén, Jeanine Diller, Gary Felder, Jim Henle, Brian Kierland, Amanda Landi, Bradley Monton, Dan Neilson, Ellina Nektalova, Aaron Smith, Gillian Tisdale, Carol Zaleski, the philosophy department at Smith College, my students in Philosophy of Religion, and the anonymous referees for this journal. 